\title{
As contradições conciliadas. Narrador, personagem e ponto de vista no Gattopardo

\author{
Raffaele Donnarumma
}

1.

Alguma coisa não se enquadra no longo discurso que padre Pirrone, recém-chegado ao vilarejo natal, vindo de Palermo, tem em frente a Dom Pietrino, um velho ervanário tão incapaz de compreender o que lhe é dito que adormece. O jesuíta de Gattopardo empenhase numa apologia tão apaixonada da aristocracia quanto narrativamente desnecessária: por um lado porque a parte em que é colocada, a quinta do romance, é claramente excêntrica (juntamente com a oitava, é a única a não ter o foco sobre o príncipe, de tal modo que, se fosse abolida, o enredo não ressentiria muito a sua falta); ${ }^{1}$ por outro, porque, frente a semelhante auditório, o religioso poderia tranqüilamente economizar seus esforços argumentativos e emotivos. Porém, surpreendido pela mãe a discursar, apenas lhe resta "envergonhar-se um pouco".

Não se trata de uma siciliana 'mala figura', menos ainda de uma suposta traição de classe. Como jesuíta, Pirrone deve defender os nobres; além disso, embora não tenha vindo de uma família de senhores, seu pai, administrador de feudos eclesiásticos, ao morrer, havia deixado o filho "em condições econômicas relativamente boas" sido um pobretão, seria espantoso surpreendê-lo em comportamentos jacobinos. O ervanário - único personagem verdadeiramente plebeu ao qual é concedida a palavra dentro do romance - demonstra-se também mais realista que o rei e mais reacionário que o jesuíta. Ele certamente se lamenta das taxas que o novo governo da casa de Sabóia impôs até mesmo sobre sua mísera atividade, e chega a chamar de "bobo" o príncipe de Salina; ${ }^{4}$ mas não lhe aflora nem mesmo a idéia de contestar a ordem feudal. Preso na lógica das aparências, mesquinha e venal, ele não pode certamente ver, como os senhores, que "não houve nenhuma revolução e que tudo continuará como antes" . No final das contas, o "bobo" é ele.

Estamos, em suma - e é talvez isso que não se ajusta - frente a um paradoxo: no único capítulo em que Dom Fabrizio, ainda vivo, está ausente da cena, exprime-se uma ideologia que é de todo modo a sua. A tarefa de padre Pirrone é simplesmente aquela de se referir a essa ideologia e explicar seus conceitos. Sendo um bom jesuíta, ele deve amenizar as dificuldades, eliminar motivos de escândalo, justificar, como se comentasse um passo das Escrituras que fosse pouco claro, ou que estivesse aparentemente em contraste com a doutrina da Igreja. A sua apologia é a absolvição de toda a classe nobre. Padre Pirrone não saiu de fato do palácio de San Lorenzo ou de Donnafugata: fazendo-se porta-voz e defensor do príncipe, ele se torna um alter ego de Dom Fabrizio, ${ }^{6}$ sua transposição sobre um plano mais baixo, porém sendo sempre uma transposição. 
2.

Trata-se, portanto, um romance em que não se dá voz ao outro? Essa é uma hipótese que parece passível de ser desmentida facilmente. Deixemos de lado Ciccio Tumeo: ele reproduz com raiva a lógica de Padre Pirrone e, justamente pela sua incapacidade de controle (e de adaptação), torna-se um "estúpido" que não sabe ver a resistência de "costumes seculares" por trás das mudanças ${ }^{7}$. Mas será que Tancredi pensa como Dom Fabrizio? Ou Dom Calogero Sedàra? E o bom Chevalley? A força de um outro ponto de vista deveria estar na manutenção de sua resistência e irredutibilidade. Ora, nem Tancredi, nem Sedàra, nem o enviado piemontês são respeitados enquanto sujeitos diferentes: pelo contrário, acabam sendo reabsorvidos por Dom Fabrizio ${ }^{8}$. Cada um deles poderia ser um antagonista; nenhum o é de fato. É exatamente com o sobrinho que o príncipe aprende sua sabedoria política, ou pelo menos é impulsionado a confrontar-se com os novos tempos; e, se é verdade que está ligado ao jovem por uma relação paterna sombreada pelo edipianismo, de algum modo a hostilidade é sublimada, como nota a princesa Maria Stella, por uma espécie de enfatuamento9. Quanto a Dom Calogero, cuja ameaça é sempre atenuada pelo ridículo, o príncipe chega a nutrir uma "curiosa admiração" pelos seus "méritos", ${ }^{10}$ e a tratá-lo com benevolente condescendência. Chevalley, enfim: o diálogo com ele é a ocasião mais gloriosa para que o príncipe diga aquilo que pensa; e a sabedoria de Dom Fabrizio mostra-se tão alta que o interlocutor reconhece suas "orgulhosas verdades", 11 mas sem compreender "todas as coisas"12. De resto, é parcialmente verdadeiro que esse seja de fato um diálogo. A um certo ponto, Dom Fabrizio está "muito excitado" "para escutá-lo"; ${ }^{13} \mathrm{e}$ na despedida os dois saúdam-se pensando coisas opostas, sem comunicá-las e sem ter mudado de opinião. A simpatia e a estima que o príncipe tem pelo enviado da casa de Sabóia só servem para ressaltar a tragicidade de sua posição. Logo em seguida, ele não fala mais de política e de escolhas, mas de um destino imutável: aquele de uma "geração desgraçada sobreposta entre os velhos e os novos tempos", ${ }^{14}$ e aquele de toda uma terra na qual o privilégio de serem "perfeitos" como "deuses" 15 confunde-se com o tormento de "serem segregados no mesmo poço", ${ }^{16}$ em um "inferno ideológico" ${ }^{17}$. A história é substituída pela natureza; e as designações de realidade adquirem subitamente o valor de metáforas e de categorias do espírito:

Esta violência da paisagem, esta crueldade do clima, esta tensão contínua de tudo o que se vê, também estes momentos do passado, magníficos mas incompreensíveis porque não foram edificados por nós, e que nos rodeiam como belos fantasmas mudos; todos estes governos, desembarcados em armas Deus sabe onde, imediatamente servidos, depressa detestados e sempre incompreendidos, que se manifestaram tão-somente por obras de arte para nós enigmáticas e por concretíssimos cobradores de impostos, despendidos depois algures: todas essas coisas formaram o nosso caráter, que ficou assim condicionado por fatalidades exteriores tanto como por uma terrível insularidade de ânimo. ${ }^{18}$

O pensamento de Dom Fabrizio é, com efeito, um pensamento de reconciliação. Nisso reside grande parte de sua fidalguia, bem diversa do recluso orgulho feudal de casta e da antiga vontade de separar o nobre do ignóbil, preservando a pureza da aristocracia. Em um certo sentido, Dom Fabrizio já se degenerou em relação a seus avós ${ }^{19}$. Não errou 
completamente a mulher ao reprová-lo por misturar o próprio sangue àquele do "velhaco" Sedàra, enganado pelas vigarices de Tancredi, "traidor" "como todos os liberais da sua espécie";20 e ele mesmo reconhece em si algo de "ignóbil" 21 . Para além de uma nietzschiana admiração pela energia e de uma vontade de potência (semelhante àquela dos grandes burgueses de Thomas Mann) ${ }^{22}$, o príncipe tem uma vocação niilista que, se não fosse pelos seus traços céticos ${ }^{23}$ e epicuristas, iria torná-lo um schopenhaueriano. Sua aspiração é a morte como "nirvana" 24 . É uma contradição apenas aparente aquela pela qual um orgulhoso defensor da identidade, e da aristocracia como sua verdadeira expressão, ${ }^{25}$ encontra paz somente na anulação de si. Isso porque a morte anula aquilo que é contingente para salvar o eterno: realiza a aspiração de "superar e justificar o seu extremo sofrimento como uma necessidade geral" 26 . Frente à quietude da morte, toda mudança terrena se torna vã. A única forma de história que Dom Fabrizio pode conceber é a história natural, cíclica, previsível, que lhe ensina a astronomia, na qual cada mudança revela o eterno retorno ao idêntico. Ela mostra como exorcizar o trauma das reviravoltas da história humana ${ }^{27}$. Para o narrador da Recherche o Bal des Têtes é a revelação do tempo perdido, que somente a arte poderá vencer. Para o príncipe de Salina, o baile no palácio Ponteleone é o conhecimento da morte e da miséria humana, das quais se defende tendo esperança na própria morte, isto é, no próprio eternizar-se, e observando os movimentos celestes:

A verdade era que queria alcançar um pouco de conforto olhando as estrelas. Havia ainda algumas ali mesmo em cima, no zênite. Como sempre, vê-las reanimou-o: sempre longínquas, onipotentes e ao mesmo tempo tão dóceis aos seus cálculos; o contrário precisamente dos homens, sempre por demais próximos, débeis e no entanto tão recalcitrantes. ${ }^{28}$

Não é a arte que salva, mas a ciência: não é a obra dos homens, mas a contemplação da natureza. Por trás do príncipe de Salina divisa-se o vulto de Tomasi: verdadeiro literato e profundamente fiel aos valores humanistas, ele não está, no entanto, imune ao sentido de inaptidão e à consciência de falta de atualidade e de marginalidade da literatura, próprios da sua geração ${ }^{29}$.

Nessa fuga das misérias da terra, completa-se o exorcismo daquele mal que é a alteridade. Ela tem duas formas: a humanidade, perecível, frágil e imprevisível, e o tempo, que nos aliena de nós mesmos; mas existe um lugar privilegiado, no qual aquelas duas formas se encontram: a história. Encontramo-nos então diante de um romance não somente anti-histórico, mas que coloca em dúvida as próprias categorias constitutivas do romance: o diálogo com o outro e o tempo.

3.

Na origem, o nó de Gattopardo talvez esteja não na relação entre o protagonista e os outros personagens, mas naquela entre o narrador e o protagonista. Não é por acaso que a esse propósito se tenha escrito tanto, e que se inicie ainda desse ponto L'Intimità e la Storia di Francesco Orlando. Analisando bem, o Gattopardo não parece simplesmente um romance 
monológico, no qual vozes heterogêneas são admitidas para serem reconduzidas a uma única, subordinadas a ela e nela superadas ${ }^{30}$. Tolstói (que Bakhtin indica como modelo desse tipo romanesco e que Lampedusa relia pouco antes de iniciar o seu livro ${ }^{31}$ ) pode construir os próprios personagens, pelo menos em certos momentos, como seus portavozes; mas, sempre, de algum modo, põe uma distância entre si e o mundo deles. Assim, n'A Morte de Ivan Ilitch, com freqüência aproximada à última parte do Gattopardo, ${ }^{32} \mathrm{O}$ protagonista resiste à morte, e, só ao final, por um abalo que o transcende, aceita-a. A sabedoria emprestada a ele pelo narrador-Deus coincide, em seguida, com a saída dos seus próprios limites e a negação de si. É o exato contrário do que acontece com Dom Fabrizio, que "conhecia desde sempre" 33 o sentido da morte, e ao qual Lampedusa dá a voz no momento decisivo.

A relação entre narrador e protagonista em Tomasi é efetivamente mais fugidia que a do romance monológico: não é suficiente para exauri-la, nem, de uma parte, a constatação do indubitável acordo simpatético entre o narrador e o príncipe de Salina, nem, de outra, a distinção narratológica entre os dois pontos de vista. Não existe nenhuma inconciliabilidade entre simpatia por um personagem - ou, no limite, projeção autobiográfica - e a onisciência. Mas não existe somente se narrador e personagem são pessoas distintas: somente se o personagem, por mais projetivo e autobiográfico que seja, é um outro em relação ao narrador. Certamente há no Gattopardo uma evidente e explícita distância entre narrador e personagem. No entanto, ela é de ordem puramente material: o narrador vê espaços que estão fechados ao olhar de Dom Fabrizio (como na parte V); ou ainda prenuncia eventos que se desenvolverão em um tempo no qual Dom Fabrizio não estará mais vivo. ${ }^{34}$ Essa distinção narratológica corre o risco, porém, de ter um significado extrínseco e formal. Embora o narrador conheça mais coisas que Dom Fabrizio, não tem uma sabedoria completamente superior à do personagem e nem mesmo valores distintos dos dele. $\mathrm{O}$ seu ponto de vista (tomando a metáfora literalmente) pode ser diverso daquele do príncipe. Mas também será diverso - o que mais conta - seu nível de consciência? Um exemplo pode nos ajudar:

Dom Ciccio desabafara. À sua autêntica ainda que rara personificação do "austero homem de bem" juntava-se outra, bastante mais freqüente, não menos genuína do esnobe. Porque Tumeo pertencia à espécie zoológica dos “esnobes passivos”, espécie hoje injustamente desprezada. Bem entendido, a palavra esnobe era desconhecida na Sicília de 1860; mas, como já antes de Koch existiam tuberculosos, assim já naqueles tempos remotíssimos existiam as pessoas para quem obedecer, imitar e, sobretudo, não molestar quem julgam pertencer a uma condição social superior à sua é a suprema lei da vida: o esnobe é, de fato, o contrário do invejoso. Nesse tempo apresentava-se sob nomes diversos: era chamado de "devotado", "dedicado", "fiel"; a vida corria-lhe feliz porque o mais vago sorriso de um senhor era suficiente para inundar de sol todo o dia; e como ele se apresentava acompanhado daqueles adjetivos afetuosos, os favores restauradores eram mais freqüentes então. A cordial natureza esnobe de Dom Ciccio fez com que ele receasse ter aborrecido Dom Fabrizio e a sua solicitude apressou-se a procurar os meios de afugentar as sombras acumuladas, segundo ele pensava, no sobrecenho olímpico do príncipe; o meio mais idôneo no momento era propor que se retomasse a caça; e assim foi feito. ${ }^{35}$

Pode parecer que o narrador tem uma consciência superior em relação àquela de Dom Fabrizio: chega mesmo a sublinhar sua distância da "remotíssima época" na qual se 
desenvolve a ação, assumindo o papel irônico do paleontólogo. No entanto, não é assim. O narrador conhece uma palavra que Dom Fabrizio, como qualquer um na Sicília de outubro de 1860, não poderia conhecer; mas usa uma categoria da qual Dom Fabrizio poderia estar totalmente ciente: aquela de "devotado", "dedicado", "fiel". E Dom Fabrizio a conhece tão bem que seu próprio comportamento é controlado a partir dela: somente porque se sabe um esnobe passivo é que perdoa a intemperança de Tumeo. O narrador então desce da sua superioridade temporal para colocar-se no plano do personagem: injusto é o presente, e, portanto, não compreende o que seja um esnobe, não o passado; é o "agora" que não dispensa mais "graças restauradoras", enquanto antigamente eram estabelecidas relações humanas eqüitativas e dignas. Desse modo, ele se libera dos preconceitos da atualidade para reassumir o verdadeiro saber do mundo sobre o qual narra.

De fato, Tomasi não pretende julgar Dom Fabrizio, colocando-se realmente de fora ou acima dele. Eis um outro, pequeno exemplo:

\begin{abstract}
Atravessando as duas divisões que o separavam do gabinete, imaginou ser um imponente leopardo de pêlo liso e perfumado que se preparava para despedaçar um chacalzinho amedrontado; mas, por uma daquelas involuntárias associações de idéias que são o flagelo das naturezas como a sua, veio-lhe à memória a imagem de um daqueles quadros históricos franceses nos quais desfilam marechais e generais austríacos, no ato da rendição, carregados de decorações e penachos, perante um Napoleão irônico $(. . .)^{36}$
\end{abstract}

Em um primeiro momento, parece que o narrador observa o príncipe de fora: somente ele, de fato, pode julgar que o personagem 'tenha imaginado'. Na realidade, essa consciência é rapidamente lançada na psicologia do personagem: a adversativa ("mas, por uma daquelas involuntárias associações de idéias...”) revela-nos logo que ele compreende o que lhe está acontecendo.

Até mesmo a ironia sobre ele é uma falsa cadência: o seu objetivo não é certamente diminuí-lo, mas, pelo contrário, emprestar-lhe uma quarta dimensão. Produz o mesmo efeito que produziria a auto-ironia ${ }^{37}$. Quando Tancredi reprova o ‘tiozão’ por ser um grande libertino (por, na sua idade, ainda freqüentar certas mulheres), está diminuindo-lhe a estatura ou celebrando a vitalidade? Não está talvez fazendo um jogo, visto que o príncipe já procura confirmações para o fato de ser "um homem vigoroso ainda" 38? E quando o narrador o faz citar uma "poesia extravagante", atribuída a "um daqueles poetas que a França desenforna e esquece toda semana", ${ }^{39}$ que é nada menos que o Baudelaire de Un Voyage a Cythère; ou o faz ler em família um "romance moderno" "capítulo a capítulo", ao invés de um Balzac recusado como "extravagante e de idéias fixas", 40 quer verdadeiramente ridicularizar a incompetência literária de Dom Fabrizio? Ou não lhe ressalta a "rigidez moral", ${ }^{41}$ sem lhe negar "uma certa perspicácia" de julgamento, ${ }^{42}$ e a capacidade de ter decorado os versos de um dos maiores poetas do século, além do mais, folheado casualmente em uma livraria parisiense?

Tomasi comporta-se com o príncipe exatamente como padre Pirrone: pode denunciar-lhe os erros, mas o julga com as categorias dele; e por fim o absolve. ${ }^{43} \mathrm{~A}$ excepcionalidade do Gattopardo, isto é, o fato de ser o único romance sobre o declínio da aristocracia escrito de um ponto de vista interno a ela ${ }^{44}$, tem o preço desse achatamento que é a anulação do outro. Diversamente de qualquer outro personagem ("Em minha casa 
ninguém me compreende. É a minha desgraça" ${ }^{45}$ ), o narrador é o único a compreendê-lo e conhecê-lo profundamente. Nesse sentido, a vantagem material do ponto de vista do narrador sobre o protagonista revela o narrador muito mais como uma projeção do personagem, literalmente, do que o contrário.

4.

A coerência com a qual Gattopardo é construído responde a uma poética que se pode reconstruir graças às lições de literatura inglesa e francesa ministradas por Lampedusa entre novembro de 1953 e 1955 (portanto, próximas, se não contemporâneas, à redação do romance). É a interpretação de Stendhal, tendenciosa já que em débito com La Crèation Chez. Stendhal (1951) de Jean Prévost ${ }^{46}$, a se mostrar particularmente reveladora ${ }^{47}$. De $O$ Vermelho e o Negro e d'A Cartuxa de Parma (Tomasi não consegue se decidir sobre qual dos dois deveria ser considerado "o vértice de toda a narrativa mundial"48) são apreciados os aspectos caracterizadores da técnica romanesca: "o modo de exprimir o tempo, de concretizar a narração, de evocar o ambiente, de tratar o diálogo"; ${ }^{49}$ assim como particular atenção é posta sobre o "problema crucial" "do narrador" 50 e sobre sua posição no confronto com os personagens. No entanto, exatamente para esse último aspecto, a chave de leitura é lírica. ${ }^{51}$ Certamente, em Stendhal "existe uma ligeira ironia espalhada sobre tudo" 52 e ele faz mover os seus personagens, até mesmo nos momentos mais patéticos e romanescos, "em uma calma divina" 53. Mas o afastamento do classicismo e da ironia une-se à vontade de narrar "permanecendo sempre na pele do próprio protagonista; e já que o mundo é visto através dos olhos deles, também o leitor contempla através daquela mente." $54 \mathrm{O}$ lirismo não é uma simples projeção do narrador sobre o protagonista, nem a redação de uma autobiografia ideal: ele permite alcançar a "completa fusão do autor, do personagem e do leitor" 55 Toda distância é anulada: o que prejudica, poder-se-ia dizer, o efeito estético. Até mesmo o adorado Dickens, com todo o seu "realismo mágico" 56 e o seu humorismo, "descreve seus personagens 'liricamente', colocando-se sucessivamente na pele de cada um, enquanto Thackeray os olha com um certo distanciamento, julga-os com serena imparcialidade e não se afeiçoa a nenhum deles" [1060]. A ironia ou a ridicularização aberta (que no Gattopardo pertencem respectivamente aos personagens principais e aos secundários) não rompem, em suma, o lirismo: o julgamento que elas exprimem ou deixam subentender diz respeito aos valores comuns do narrador e do príncipe; assim se consolida o pacto entre os dois e se convida o leitor a participar dele.

Tomasi tem de fato idéias muito claras sobre como alcançar essa "completa fusão":

Tal resultado é em grande parte obtido mediante o "monólogo interior". Esse procedimento, que seria levado ao próprio acme por Proust, Joyce e Woolf, é usado por Stendhal com a mais clássica medida, indispensável para não retardar a ação mesmo que revelando seus motivos. O que parece fácil, mas não é. O vermelho e o negro é, principalmente, uma efusão lírica e um romance de análise psicológica, mas é também uma pintura do tempo e um livro no qual os fatos pressionam. Essa última necessidade não aparece certamente nas obras dos três autores mencionados cinco linhas acima. Dessa necessidade de ação deriva 
um esforço de concentração dos "monólogos interiores" que não se encontra naqueles autores para os quais esse meio de expressão havia se tornado um fim..$^{57}$

O julgamento crítico acima diz muito sobre o modernismo classicista de Lampedusa, ${ }^{58}$ que reconduz as inovações do Novecento à medida do romance do Ottocento, neutraliza-lhes o caráter subversivo graças a uma categoria de todo modo tradicional como aquela do lirismo, prefere de fato ao "monólogo interior" uma focalização interna mais praticável. E diz muito sobre o Gattopardo, ao qual é possível aplicar, palavra por palavra, a definição de $O$ Vermelho e o Negro, incluindo o redimensionamento do epíteto de "romance histórico" atribuído a ele um pouco antes ${ }^{59}$. Com toda a simpatia por Stendhal e a vontade de se fazer discípulo dele, ou até mesmo de encontrar nele autorizações para a própria escrita ${ }^{60}$ Tomasi afasta-se do escritor francês, porém, em algum ponto relevante. Além da diferença do estilo, "gordo" mais do que "magro", ${ }^{61}$ pelo menos nisto: também ele, diversamente do mestre, incorre no "defeito de tantos romances (e entre eles alguns dos maiores!) de revelar o ânimo das pessoas através daquilo que dizem" ${ }^{62}$. Não é pouca coisa: não tanto porque exponha a riscos de irrealismo, didascalismo ou ideologismo; mas exatamente porque parece mudar a postura do narrador no confronto com os personagens, aos quais vem atribuída uma lucidez que parece faltar aos heróis stendhalianos. Porém, também essa é uma escolha de poética: dada a "completa fusão do autor, do personagem e do leitor", eles devem gozar todos da mesma consciência. Uma sabedoria separada do narrador, e exercitada em detrimento do protagonista, romperia com aquele lirismo no qual a presença de vozes diversas é só aparência. Todo discurso é, ao mesmo tempo, discurso do personagem e do narrador (do narrador, não do autor), que se "coloca na pele do outro". Indubitavelmente, Dom Fabrizio "não é Lampedusa", mas "o fantástico êxito de um apagamento do desejo"63 - exatamente como acontece com Stendhal, Julien e Fabrice. Porém o livro funciona como se Dom Fabrizio fosse o autor - exatamente como queriam Lampedusa $^{64}$ e, se não Stendhal, o Stendhal de Lampedusa.

\section{5.}

“O monólogo interior” ou, de modo mais geral, a focalização interna, são ambos um ato de verdade em dois casos opostos: quando o personagem entra em diálogo com um outro ponto de vista, seja aquele do narrador ou de um personagem diferente; ou quando é abandonado a si mesmo, na sua 'criaturalidade'. O Ulysses de Joyce, para permanecer entre os autores de Lampedusa, acolhe ambos os modos, enquanto Proust evita a unidimensionalidade através da riqueza dos mundos representados e da difração do eu em agens e auctor. Quanto à Woolf, cujos Anos inspiram de algum modo a estrutura do Gattopardo ${ }^{65}$, a tentação do lirismo é mais forte, mas contrasta com a pluralidade das pessoas líricas (basta pensar na dupla focalização interna de Mrs. Dalloway, em Septimus, e na protagonista, ou naquela múltipla d'As Ondas e mesmo d'Os Anos). Desse modo, o monólogo interior é uma dispersão de si no outro, ou no atomismo dos pensamentos e das sensações de quem fala ${ }^{66}$. Em Tomasi, ao contrário, a focalização interna coopera para a constituição de um personagem que não perde a unidade ao se facetar, mas a conquista. O projeto, logo 
abandonado, ${ }^{67}$ de escrever um romance todo resolvido em vinte e quatro horas, como o Ulysses, sobrevive na escansão cronológica da parte I sob a condição de uma drástica redução. Os flash-backs mnemônicos, que seguem as "associações de idéias" de Dom Fabrizio, ${ }^{68}$ não são certamente a derivação de vozes colocadas em cena por Joyce: eles não exprimem uma tensão centrífuga e enciclopédica em direção à vastidão do mundo, mas se fecham centripetamente na interioridade do príncipe. Nisso Tomasi prefere, à escandalosa tensão do stream of consciousness de Joyce, a recomposição que lhe dá Woolf, normalizando seu lirismo e acomodando-o em uma irônica unidade aristotélica. Mais do que lançá-lo entre as coisas ou desconstruir o seu protagonista, Tomasi se une a ele e sobre ele modela o mundo.

A verdade de um personagem romanesco está também no ato de violência com o qual o narrador mostra o caráter parcial e mortal $^{69}$ desse personagem. Mas Tomasi recusa essa violência. Ele se apóia na categoria do lirismo, pois sabe que o personagem lírico é subtraído à morte. Mesmo quando reflete sobre a própria finitude, de fato, este último já a transcendeu. $\mathrm{O}$ personagem romanesco, pelo contrário, está sempre submetido à morte (ao passo que não é impossível imaginar formas narrativas que eliminem essa ameaça, como todas aquelas - da épica à fábula, da lenda ao apólogo - que têm relações com o mito). No entanto, também o romance pode reservar um espaço a uma voz não tocada pela morte: aquela do narrador, com a condição de que ele seja o menos possível identificado como personagem e ligado à contingência. Se a voz do narrador vem de um ponto impreciso, se não tem história nem registro, corpo nem nome, então a sua voz não é mortal e a sua sabedoria, o que quer que saiba, é mais alta do que a de um homem.

O narrador de Gattopardo seria um narrador desse tipo, já que, ainda que exprima julgamentos, não se representa jamais como personagem, preferindo, entretanto, em um certo sentido, renunciar a parte de seus privilégios, transferindo-os ao seu protagonista. Por isso procura de qualquer modo preencher a distância entre si e Dom Fabrizio, o qual, enquanto personagem lírico, goza de um privilégio que deveria ser só seu: a vitória sobre a morte. Diminuído e relativizado será, portanto, não o protagonista, salvo o quanto possível do horror da finitude, mas justamente o narrador. Tomasi recusa-se até o fim ser um narrador onisciente. O olhar do narrador onisciente é o olhar da totalidade. Essa é, no fundo, a especificidade do seu nível de consciência. Mesmo quando ele retrata personagens perfeitamente sábios (isto é, substancialmente, personagens porta-vozes), goza ainda de uma vantagem sobre eles: aquela de ser dono de seus destinos e de poder transcender a individualidade deles, inserindo-a em um desenho mais totalizante. Ao contrário, aquilo que o narrador do Gattopardo exibe é a fragmentação do tempo. Dessa maneira, ele se põe ao nível do príncipe e o faz de modo que a própria sabedoria seja duplicada da sua. A estrutura do livro, já demonstrada como lacunosa, corresponde à reconstrução da própria vida encerrada com Dom Fabrizio agonizante. O elenco de coisas, pessoas e momentos que o fizeram feliz parece superar a unidade de uma consciência que quer sanar toda contradição no conhecimento da morte. A vida verdadeira destaca-se como exceção de um fundo compacto de não-vida, do qual não se pode narrar nada: "Tenho setenta e três anos, dentre eles terei vivido, verdadeiramente vivido, aproximadamente um total de dois... três anos no máximo." 70 Mas essa verdadeira vida existe e se abre epifanicamente como lírica plenitude de sentido. Ao narrador só resta unir em um colar estas pérolas: exatamente 
ao contrário de Proust, cujo problema é reconhecer os vazios e resgatá-los, e eventualmente seguindo Woolf, que reúne n'Os Anos cenas e fragmentos subtraídos do silêncio. Além de fruto de um consciente novecentismo, o enfraquecimento do narrador parece o necessário e melancólico preço pago aos tempos de saudosismo de um antigo modo de narrar.

Por fim, frente às figuras de contorno, Tomasi recupera os privilégios do narrador onisciente. Aqui, completa-se o ato de violência que põe sobre o personagem os sinais da morte. Por isso, padre Pirrone, Sedàra, Chevalley, o coronel Ponteleone, ou mesmo mulher e filhos do príncipe são objeto de uma representação que foi resolutamente tachada de bozzetismo ${ }^{71}$ e que tem, eventualmente, traços satíricos. A sátira achata o personagem em um tipo e o priva da densidade do indivíduo somente para denunciá-lo na sua finitude. Assim, Lampedusa interdita aos personagens secundários e figurantes o acesso à verdade, reservando-a somente ao protagonista. Os outros podem também colher alguma coisa do sentido da história e participar dela, de modo ativo ou passivo; mas nenhum deles, nem mesmo Tancredi, intui aquele sentido último que Dom Fabrizio encontra para além da história, na contemplação das estrelas e no cortejar a morte. Desse modo, restaura-se a separação da Stiltrennung entre personagens nobres e personagens que não o são, até mesmo deslocando o critério do sangue para o espírito ${ }^{72}$. A vida quotidiana, ainda que objeto de contemplação estética e de gozo sensual, aparece degradada na escala do ser e invadida pela obsessão mortuária ${ }^{73}$ que convém à vaidade do inautêntico. O realismo romanesco é assim o véu sob o qual vive a nostalgia, de origem lírico-trágica, por valores que negam a contingência.

6.

Pode-se admirar a coerência do Gattopardo, mas é possível também se espantar com as contradições que o atravessam, e com a vontade de conciliá-las. Dom Fabrizio é ao mesmo tempo sensual e místico, como já o eram seus avós, que deixaram no palácio de Domnafugata um quarto para o sadismo e a autoflagelação; Tancredi trai a estirpe, mas é o único que a faz sobreviver verdadeiramente; Dom Calogero Sedàra é um homem vulgar, mas também merece admiração; Chevalley é animado pelos mais nobres propósitos, mas não compreende a realidade; Dom Ciccio Tumeo opõe-se ao príncipe, mas exprime a ideologia deste; a princesa Maria Stella tem impulsos histéricos de muda rebelião ao marido, mas goza ao sentir-se dominada; a Sicília é uma terra de perfeições e de tormentos; a mudança da história existe e não existe; tudo muda e tudo permanece igual.

Se há uma figura sob a qual inscrever o Gattopardo, esta não é nem a antífrase, nem o oxímoro, ${ }^{74}$ nos quais os opostos convivem sem serem superados, mas sim aquela sua conciliação que é a ambigüidade. Sinal supremo da ambigüidade é a última parte do romance. Para ser exato, o romance tem dois finais: a parte VII, com a morte de Dom Fabrizio, e a VIII, com o "fim de tudo". O díptico rege-se em primeiro lugar a partir da oposição: se o primeiro elemento, inteiramente sobre e de Dom Fabrizio, transcende o contingente e se afirma como poesia; o segundo é totalmente posterior a Dom Fabrizio, não vê nada além de coisas finitas, encerra-se em uma prosa amarga e desencantada, flaubertiana ${ }^{75}$. 
No entanto, Tomasi não devia manter semelhante conclusão em contraste com o projeto de romance lírico. Isso, de fato, já está no romance lírico por excelência, $O$ Vermelho e o Negro:

As não poucas páginas que se seguem ao delito de Julien são muito singulares: o mundo não é mais visto através de Julien, mas através de uma terceira pessoa indiferente e apagada. Como Julien podia de fato sentir se, para o autor, ele já estava morto? ${ }^{76}$

De resto, as últimas páginas do Gattopardo também têm uma focalização interna: não mais sobre o príncipe, mas sobre a única entre os seus filhos que ele sente como "uma verdadeira Salina", ${ }^{77}$ Concetta, que é também, deixando salva a fusão entre personagem e narrador, a segunda figura do romance com um autobiografismo ${ }^{78}$.

Mas em que sentido assistimos ao fim de tudo? Não devemos recordar que para Dom Fabrizio, "como conclusão, a sua morte era em primeiro lugar aquela de todo o mundo"79? Sem o seu protagonista, o narrador reduz a sua voz à de um fantasma. O "vazio" torna-se "completo". ${ }^{80}$ No momento em que se recusa a constituir um sentido para o mundo, o narrador concede ao seu protagonista o tributo mais alto: somente ele poderia dar esse sentido. A tragédia da extinção não é uma tragédia histórica, mas individual. Aquilo que morre com Dom Fabrizio não é a aristocracia dos Borbons, mas o sentido real, profundo, inteiro da identidade:

Era inútil tentar acreditar no contrário: o último Salina era ele, gigante mirrado que agonizava agora na varanda de um hotel. Porque o significado de uma linhagem nobre está todo nas tradições, quer dizer, nas recordações vitais: e ele era o último a possuir recordações insólitas, distintas das outras famílias. ${ }^{81}$

O mundo posterior ainda irá se sair muito bem: não com as três pobres velhas solteiras, mas com Tancredi, depois com o agressivo Fabrizietto. Mas será o mundo da massa, no qual não há mais lírica, porque agora não há mais eu.

Notas

1 Notava-o já E. Montale, Il Gattopardo [1958] in E. MONTALE, Il Secondo Mestiere. Prose 1920-1979, a.c. de G. ZAMPA, Milano, Mondadori, 1996, vol. II, pp.2169-75, a. p. 2171. A parte foi de fato composta depois das outras, e Tomasi foi tentado a aboli-la (G.P. SAMONÀ, Il Gattopardo, i Racconti, Lampedusa, Firenze, La Nuova Italia, 1974, pp. 129-48 e 210-5); o que, naturalmente, não significa que seja estruturalmente inútil.

2 Citado de G. TOMASI DI LAMPEDUSA, Opere, introd. e premesse di G. LANZA TOMASI, a cura de N. POLO, Milano, Mondadori, 1995. P. 189.

3 Ibid. p. 179.

4 Ibid. p. 189.

5 Ibid. p. 189.

6 V. BRAMANTI, Rileggendo "Tl Gattopardo", in “Studi novecenteschi”, 1988, n.36, pp. 323-48, às pp. 333-4 e

345; F. ORLANDO, L' Intimità e la Storia. Lettura del “Gattopardo”, Torino, Einaudi, 1998, p.98.

7 G.P. SAMONÀ, op. cit, p.121-2. 
8 Já o afirma F. FORTINI, Contro "Il Gattopardo" [1959], in F. FORTINI, Saggi Italiani, Milano, Garzanti, 1987, pp. 261-71, às pp. 261-3 e 271; argumenta mais analiticamente V. SPINAZZOLA, Il Romanæo Antistorico, Roma, Editori Riuniti, 1990, pp. 191-5 e 215-24.

9 Op. cit. p. 100. Tancredi é "o Outro" por excelência, segundo F. ORLANDO, L'Intimità e la Storia, cit., p. 131.

10 Op. cit. p. 132.

11 Op. cit. p. 175.

12 Op. cit. p. 171.

13 Op. cit. p. 173.

14 Op. cit. p. 173.

15 Op. cit. p. 176.

16 Op. cit. p. 175.

17 Op. cit. p. 173.

18 Op. cit. Pp. 172-173. Passo a indicar, a partir daqui, também as páginas da seguinte edição brasileira, de que me servi para os trechos destacados: O Leopardo. Trad. Leonardo Codignoto. São Paulo: Editora Nova Cultural, 2002. p. 210. [N. do T.]

19 R. LUPERINI, Il "gran signore" e il dominio della temporalità. Saggio su Tomasi di Lampedusa [1997], in R. LUPPERINI, Controtempo. Critica e letteratura fra moderno e postmoderno: proposte, polemiche e bilanci di fine secolo, Napoli, Liguori, 1999, pp. 133-46 a p. 140.

20 Op. cit. pp. 100-101.

21 Op. cit. p. 88.

22 M. PAGLIARA, Lampedusa e il romanzo del Novecento, in Tomasi e la Cultura Europea, Palermo, Real Albergo dei Poveri 25-26 maggio 1996, Atti del Convegno Internazionale, a. c. de G. GIARRIZZO, Catania, Università degli Studi, 1996, pp. 169-212.

23 Op. cit. p. 121 e p. 218.

24 Op. cit. p. 171.

25 Op. cit. p. 230.

26 Op. cit. p. 24.

27 R. LUPERINI, op. cit. pp. 135-9.

28 Op. cit. p. 222. (Leopardo, op. cit., p. 273).

29 Ivi, p. 142.

30 M. BACHTIN, Dostoevskij. Poetica e Stilistica, Torino, Einaudi, 1968, pp. 76-7, 94-8, 103-11.

31 G.P. SAMONÀ, op. cit., p.230.

32 Cfr. p. e. D. PERRONE, Silenzi, censure e grandi incontri di Tomasi di Lampedusa, in Lucio Piccolo. Giuseppe Tomasi. Le ragioni della poesia, le ragioni della prosa, Atti del Convegno Internazionale, Capo d'Orlando 4-6 outubro 1996, a cura di N. TEDESCO, Palermo, Flaccovio, 1999, pp. 113-138, às pp. 131-3.

33 Ibid. p. 223.

34 F. ORLANDO, L'intimità e la storia, cit., p. 88 e n.11.

35 Op. cit. pp. 114-115. (Leopardo. Op. cit. p. 136).

36 Op. cit. p. 122. (Leopardo. Op. cit. p. 145).

37 Pelo contrário, a ironia produz um efeito polifônico, segundo F. MUSARRA, Su alcune marche ironiche nel 'Gattopardo', in Gattopardo. Atti del convegno internazionale dell'Università di Lovanio, Lovanio, 13 maggio 1990, a cura di F. MUSARRA e S. VANVOLSEM, Leuven - Roma, Leuven University Press - Bulzoni, 1991, pp. 53-75, às pp. 67 e 74; e ainda mais definido é A. C. VITTI, "Dom Fabrizio e Tomasi in contrasto nel romanzo 'Il Gattopardo' ”, in Misure critiche, 1989, 68-9. A minha posição é próxima à de M. GUGLIELMINETTI, Le rotelle del meccanismo (nota sul "Gattopardo"), in Il Gattopardo. Atti del convegno internazionale dell'Università di Lovanio, cit., pp. 33-40. 
38 Op. cit. p. 36.

39 Op. cit. p. 37.

40 Op. cit. pp. 140-141.

41 Op. cit. p. 21.

42 Op. cit. p. 141.

43 V. SPINAZZOLA, op. cit., pp. 212-5.

44 F. ORLANDO, L'Intimità e la Storia, cit., p.19.

45 Op. cit. P. 73.

46 R. ADAMS MAK, Le "Lezioni su Stendhal" di Tomasi di Lampedusa, in "Yearbook of Italian Studies", 1973-

75, pp. 264-71.

47 A relação naturalmente não é mecânica, como sublinha R.M. MONASTRA, Il "Gattopardo" e la tradizizione

del romanzo storico, in Lucio Piccolo. Giuseppe Tomasi, cit., pp.59-72, a p.61.

48 Op. cit. p. 1824.

49 Op. cit. p. 1976.

50 Op. cit. p. 1799.

51 Op. cit. pp. 1766-1768, 1800.

52 Op. cit. p. 1814.

53 Op. cit. p. 1813.

54 Op. cit. p. 1815.

55 Op. cit. p. 1800.

56 Op. cit. p. 1021.

57 Op. cit. pp. 1800-1801.

58 Cfr. N. TEDESCO, La Scala a Chiocciola. Scrittura novecentesca in Sicilia, Palermo, Sellerio, 1991, p.3; R. LUPERINI, op.cit., p.146; U. MUSARRA SCHROEDER, Tomasi di Lampedusa e la poetica della "forma spaziale", in Lucio Piccolo. Giuseppe Tomasi, cit., pp.177-91.

59 Op. cit. p. 1765.

60 Como os personagens de Stendhal, também Dom Fabrizio tem uma "moral epicurista com acentos colocados sobre prazeres espirituais mais que sobre aqueles do corpo" [1768]; também ele tem um "culto da energia" de sabor nietzschiano [Op. cit. p. 1771]; também ele, nos confrontos com Tancredi, tem a tendência a indicar "a responsabilidade" dos "equívocos" na "conjuntura histórica" [1806]: tendência que o narrador também mostra em relação ao príncipe.

61 F. ORLANDO, Ricordo di Lampedusa (1962) seguito da Da diverse distanze (1996), Torino, Bollati Boringhieri, 1996, pp. 45-7 e 75.

62 Op. cit. p. 1804.

63 ORLANDO, L'Intimità e la Storia, cit., pp. 13 e 14.

64 "O protagonista sou, no fundo, eu mesmo"; "o protagonista, Dom Fabrizio, exprime completamente as minhas idéias", escrevia por carta Tomasi (in A. VITELLO, Giuseppe Tomasi di Lampedusa, Palermo Sellerio, 1987, p.230). Discute essas afirmações F. ORLANDO, L'Intimità e la Storia, cit., pp. 13 ss.

65 "The Years é o livro de Woolf que suscitou maiores controvérsias e que muitos desaprovam. Estes acham que o tema do tempo é aqui insistentemente e muito explicitamente posto. Pode ser. A mim parece o mais penetrantemente poético de todos. São episódios destacados de quatro momentos da vida de uma família, de 1880 a hoje. Entenda-se bem, não momentos cruciais, mas momentos quaisquer, carregados de uma oculta fatalidade. E os relógios da casa, que se quebram naqueles cinqüenta anos, são consertados, vendidos e comprados, mas sempre de modo que um deles permaneça a bater as horas, marcando através desse meio século o fluir persistente do tempo, tal como propõe Heráclito. Junto a eles as estações se alternam, imenso relógio cósmico, sublinhando com a sua imutável variedade a mutável identidade das gerações" [Op. cit. P. 1255]. (Diferente de Woolf, Lampedusa recupera os "momentos cruciais", deixando-os porém sobre o fundo 
dos grandes eventos públicos: as estruturas do romance histórico abafam assim o psicologismo novecentista). Cfr. U. MUSARRA -SCHROEDER, Memoria letteraria e modernità nel "Gattopardo", in Tomasi e la Cultura Europea, cit., pp. 233-55, às pp. 251-2; M. BERTONE, Le ragioni del metodo: tomasi di Lampedusa e i maestri del romanzo europeo, in Lucio Piccolo. Giuseppe Tomasi, cit., pp.45-57; R.M.MONASTRA, Il "Gattopardo" e la tradizione del romanzo storico, cit.; N. ZAGO, La estrategia narrativa del "Gattopardo" in Lucio Piccolo. Giuseppe Tomasi, cit., pp.22740; D. FIDANZA, Giuseppe Tomasi di Lampedusa e Virginia Woolf, in Giuseppe Tomasi di Lampedusa. Cento anni della nascita, quaranta dal "Gattopardo", Atti del convegno di Palermo, 12-14 dicembre 1996, a.c. di F. ORLANDO, Città di Palermo, Assessorato alla Cultura, 1999, pp. 235-57.

66 G. DEBENEDETTI, Commemorazione provvisoria del personaggio-uomo [1965], in G. DEBENEDETTI, Il Personaggio-Uomo, Milano, Garzanti, 1998, pp. 11-49, às pp. 16-9.

67 G. LANZA TOMASI, Premessa a Il Gattopardo, in TOMASI DI LAMPEDUSA, Opere, cit., p.7.

68 Op. cit. p. 23.

69 W. BENJAMIN, Il narratore. Considerazioni sull'opera di Nicola Leskov, in W. BENJAMIN, Angelus novus. Saggi e frammenti, Torino, Einaudi, 1962, pp. 247-74, às pp. 258-9 e 165-6.

70 Op. cit. p. 234.

71 Tendência a representar através de meros esboços ou traços típicos. [N. do T.]

72 G.P. SAMONÀ, op. cit., p. 108. O "retorno à hierarquia dos estilos" é ilustrado por V. SPINAZZOLA, op. cit., pp. 202-6.

73 N. ZAGO, I Gattopardo e le Iene, Il messaggio inattuale di Tomasi di Lampedusa, Palermo, Sellerio, 1983, pp. 2634.

74 S. SALVESTRONI, Giuseppe Tomasi di Lampedusa, Firenze, La Nuova Italia, 1973. p.80; E. MATTIODA, Ironia, tempo e sintassi in Tomasi di Lampedusa e Lucio Piccolo, in Lucio Piccolo. Giuseppe Tomasi, cit., pp. 139-61, às pp. $139-45$.

75 Percebe relações com Un Coeur Simple A. SERVELLO, "Ascendenze flaubertiane nel 'Gattopardo' ”, in Otto/Novecento, maggio-agosto 1980, pp. 210-5.

76 Op. cit. pp. 1807-1808.

77 Op. cit. p. 233.

78 F. ORLANDO, Ricordo di Lampedusa, cit., p.67.

79 Op. cit. p. 213.

80 Op. cit. p. 257

81 Op. cit. p. 230. (Leopardo. Op. cit. p. 284). 